\title{
Clinical Experience With a Dual Switch Valve (Miethke) for the Management of Adult Hydrocephalus
}

\author{
Akira TSUNODA and Chikashi MARUKI \\ Department of Neurosurgery, Koshigaya Municipal Hospital, Koshigaya, Saitama
}

\begin{abstract}
The dual switch valve (DSV), which switches between two parallel valve chambers depending on the patient posture, was evaluated in 101 consecutive adult patients with hydrocephalus who required shunt surgery. The opening pressure was 5 or $10 \mathrm{cmH}_{2} \mathrm{O}$ for the supine position and 30 or $40 \mathrm{cmH}_{2} \mathrm{O}$ for the upright position depending on the sitting height. The results clearly showed that the DSV can regulate the intraventricular pressure (IVP) to 5 to $10 \mathrm{cmH}_{2} \mathrm{O}$ in the supine and almost zero in the upright position, independently of posture. Ninety-four of the 101 patients received the DSV and 86 patients showed some clinical improvement. However, three patients required irrigation of subdural hematoma and six were thought to suffer underdrainage (4 probable and 2 possible). Such underdrainage probably resulted from the relatively high opening pressure in the supine position of $10 \mathrm{CmH}_{2} \mathrm{O}$ and the bedridden state of these patients. This problem may be solved by the DSV with the $5 \mathrm{cmH}_{2} \mathrm{O}$ setting in the supine position. The DSV can maintain physiological IVP in hydrocephalic patients independently of posture and provides generally satisfactory clinical outcome, but cannot prevent all inadequate drainage-related problems.
\end{abstract}

Key words: dual switch valve, hydrocephalus, intraventricular pressure, ventriculoperitoneal shunt

\section{Introduction}

Shunt complications related to inadequate cerebrospinal fluid (CSF) drainage are one focus of methods of treatment for hydrocephalus. However, the problem remains unsolved despite the introduction of a number of new devices. ${ }^{1,3,19)}$ Such overdrainagerelated problems are mainly caused by the changes in hydrostatic pressure with posture, especially negative intraventricular pressure (IVP) in the upright position. ${ }^{3)}$ A pressure-adjustable device can prevent negative IVP in the upright position if overdrainage occurs, but may cause excessively high IVP in the supine position. Essentially, pressure-adjustable devices, as well as conventional differential pressure types, cannot prevent the siphon effect completely. ${ }^{3,5)}$ The dual switch valve (DSV) acts like two reliable differential pressure valves in parallel, with different opening pressures depending on the position of the patient. Therefore, the DSV can be expected to regulate IVP physiologically independently of posture. ${ }^{12,18,20)}$

The present study investigated the use of a DSV to regulate IVP independently of the posture, and to prevent problems related to inadequate drainage.

Received October 6, 2006; Accepted June 12, 2007

\section{Materials and Methods}

The study included 101 consecutive patients, 46 males and 55 females aged 35 to 93 years (mean 63.2 years), who underwent shunt surgery between May 2000 and December 2004 at our hospital (Table 1). Written informed consent was obtained from all patients (and/or their family) before surgery.

All patients underwent ventriculoperitoneal shunting except three patients with ventriculopleural shunting. The ventricular tip of the catheter was placed in the frontal horn of the lateral ventricle and the abdominal tip was inserted through a midline upper abdominal incision into the subphrenic space. The shunt system was Silascon VP shunt type A (dual chamber type; Kaneka Medical, Tokyo) and the DSV was placed at the anterior chest wall parallel to the body axis.

The DSV contains two autonomous valve chambers with completely different opening pressures depending on the posture of the patient (Fig. 1A). If the patient is in the supine position and the IVP is higher than the strength of the weaker spring, the low-pressure chamber opens and the CSF can flow to the distal tube connection past the titanium ball, which does not close the outlet cone in the horizontal position (Fig. 1B). If the patient is in the upright 
Table 1 Profile of the 101 patients

\begin{tabular}{lc}
\hline Number & 101 \\
Sex (male/female) & $46 / 55$ \\
Mean age (range, yrs) & $63.2(35-93)$ \\
Etiology & 12 \\
Idiopathic & 89 \\
Secondary & 67 \\
$\quad$ subarachnoid hemorrhage & 16 \\
$\quad$ intracerebral hematoma & 3 \\
brain tumor & 2 \\
head trauma & 1 \\
\hline
\end{tabular}

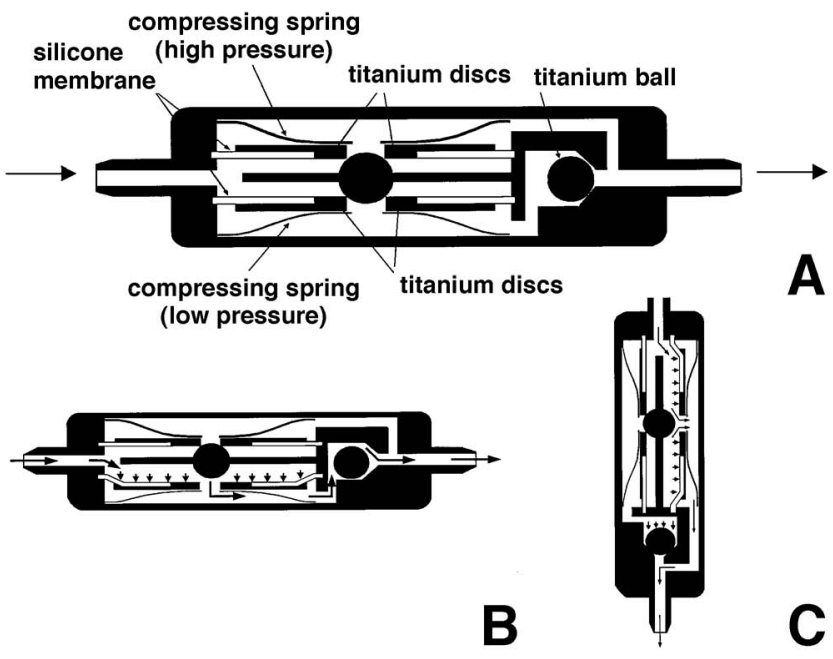

Fig. 1 A: Inner structure of the dual switch valve. B: In the supine position, the low-pressure chamber is activated. C: In the upright position, the titanium ball closes the lowpressure chamber, and the high-pressure chamber is activated.

position, gravity causes the ball to close the outlet of the low-pressure chamber. If the IVP plus hydrostatic pressure does not exceed the pressure of the stronger spring, both valve chambers remain closed and the IVP is kept within the physiological range. If the IVP is higher than the strength of the stronger spring, the high-pressure chamber opens (Fig. 1C). The DSV is available with opening pressure of 5 (available since May 2003), 10, 13, or $16 \mathrm{~cm} \mathrm{H}_{2} \mathrm{O}$ for the supine position and 30,40 , or $50 \mathrm{cmH}_{2} \mathrm{O}$ for the upright position. ${ }^{12,18)}$ We used valves with opening pressure of $10 \mathrm{cmH}_{2} \mathrm{O}$ until April 2003 (Group A, 77 cases) or $5 \mathrm{cmH}_{2} \mathrm{O}$ from May 2003 (Group B, 24 cases) for the supine position and 30 or $40 \mathrm{cmH}_{2} \mathrm{O}$ for the upright position, depending on the sitting height.

All patients underwent IVP monitoring via the shunt reservoir for 1 week after shunt placement. The patient remained in the sitting position for at least 1 hour before the measurements were taken. Measurements began with the patient in the supine position. After the opening pressure (OP1) was recorded, several bolus injections of the saline were given until a steady state was obtained, which was thought to be the shunt opening pressure (SOP) in the supine position. The patient was then tilted to the sitting position by elevating the backrest. After a sufficient interval, the opening pressure in the sitting position (OP2) was recorded. The zero reference level was at the level of the external auditory meatus for both supine and sitting positions.

The outcome was assessed at the time of the patient's last contact with our department. Outcome was determined by the effect of treatment on symptoms and signs, but not on radiological findings, and was graded as improved (some clinical improvement), no change (no apparent change in clinical condition), and worse. The follow-up period was 3 to 50 months (mean 27.4 months). IVP measurement was repeated and, if necessary, shuntgraphy was performed to confirm the shunt function if the clinical condition worsened in the observation period, or showed no improvement after shunt placement.

If shunt obstruction was verified, shunt revision was undertaken using the same type of DSV as in the first operation. If underdrainage-related problems were identified but the shunt system was patent, the DSV was replaced with a Sophy pressure adjustable valve (SPAV) to reduce the risk of underdrainage and need for further surgery until May 2003, or replaced with a DSV with opening pressure of $5 \mathrm{cmH}_{2} \mathrm{O}$ in the supine position after May 2003. If a patient developed symptomatic subdural hematoma, irrigation and drainage surgery was performed immediately. The need for further treatment, such as shunt revision with a higher pressure valve, was assessed individually. However, shunt revision was not always performed for patients in the "no change" group, if they had commensurate brain damage that had caused the original disease.

Our criteria for overdrainage and underdrainage were as follows. Overdrainage was indicated by subdural hematoma or hygroma with clinical symptoms; or symptoms clearly caused by low intracranial pressure, such as headache deteriorating in the upright position. Underdrainage was indicated by clinical deterioration despite patent shunt system and IVP within the normal range and clinical improvement after shunt replacement with a lower pressure valve. 


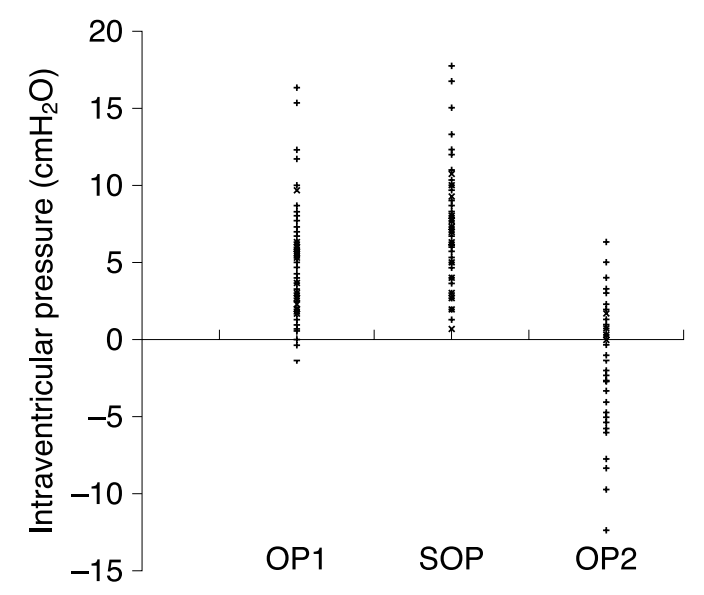

Fig. 2 Graph showing opening pressure in the supine (OP1) and sitting (OP2) positions, and shunt opening pressure in the supine position (SOP). Group A (+), opening pressure $10 \mathrm{cmH}_{2} \mathrm{O}$; Group $B(\times)$, opening pressure $5 \mathrm{cmH}_{2} \mathrm{O}$.

\section{Results}

Figure 2 shows the IVP measured at 1 week after shunt placement. Mean OP1, SOP, and OP2 were 5.6, 9.4, and $-2.2 \mathrm{cmH}_{2} \mathrm{O}$, respectively, in Group A, and $4.1,5.7$, and $-3.1 \mathrm{cmH}_{2} \mathrm{O}$, respectively, in Group B. OP1 was usually 3 to $4 \mathrm{cmH}_{2} \mathrm{O}$ lower than the SOP, which was nearly equivalent to the valve setting pressure of $10 \mathrm{cmH}_{2} \mathrm{O}$ in Group $\mathrm{A}$ and $5 \mathrm{cmH}_{2} \mathrm{O}$ in Group B. OP2 was slightly below zero in most patients, but no extremely negative pressure, less than $-15 \mathrm{~cm} \mathrm{H}_{2} \mathrm{O}$, was found in any patient.

Figure 3 summarizes the clinical progress of all patients in this series. Seventy-seven patients showed clinical improvement after shunt placement without additional surgery. Nine patients were thought to have some inadequate drainage-related problems and required additional surgery, shunt revision in six patients, irrigation of subdural hematoma in one, and both in two. Shunt obstruction was verified by shuntgraphy in six patients, caused by blockage of the ventricular catheter in five and blockage of the peritoneal catheter in one. No valve was obstructed. All patients underwent shunt revision using DSV. One patient suffered meningitis and the shunt system was removed at that time. After temporary extraventricular drainage, he has been followed up in good condition without the shunt. The DSVs remained implanted in 94 patients. Overall, 86 patients showed some clinical improvement after shunt placement and revision.

Table 2 summarizes the nine patients thought to have problems with inadequate drainage. Three

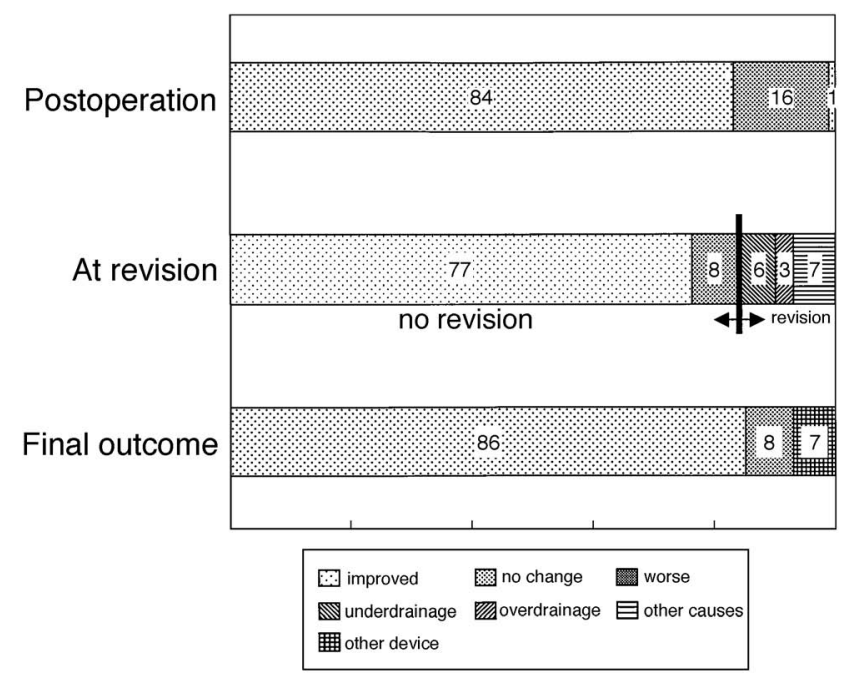

Fig. 3 Graph showing the clinical progress of 101 patients 1 week after shunt placement, at shunt revision (if operated), and at the time of their last contact with our department.

patients (Cases 1-3) showed clinical deterioration followed by temporary improvement after surgery, none of whom had any obstruction of the shunt system according to the shuntgraphy, and IVP was within normal limits in all three. Two patients (Cases 5 and 6) also showed clinical deterioration with patent shunt but slightly high IVP. These five patients were treated for underdrainage, although the latter two had suspected incomplete obstruction of the shunt system. Four patients (Cases 1, 2, 5, and 6) underwent shunt replacement with a SPAV, and Case 3 received a lower setting DSV $\left(5 / 30 \mathrm{cmH}_{2} \mathrm{O}\right)$. Case 4 was also believed to suffer from underdrainage because of no clinical improvement after shunt replacement despite the patent shunt system and normal IVP. She showed marked clinical improvement with a reduction of ventricle size after removal of the DSV, which had caused a skin ulcer on the anterior chest wall.

Three patients developed symptomatic subdural hematoma (Cases 7-9) and underwent drainage surgery immediately, 6 months, and 2 years after shunt placement. Two patients (Cases 7 and 8) suffered obvious episodes of head trauma in this period. Case 7 underwent shunt replacement, changing the DSV to the SPAV with high-pressure setting, because he showed extremely low IVP after drainage surgery although he remained in the supine position due to his general clinical situation independent of the hydrocephalus. The SPAV was implanted because the patient would clearly always remain bedridden, so a gravitational valve was not necessary. Case 8 
Table 2 Summary of nine cases with problems related to inadequate drainage

\begin{tabular}{|c|c|c|c|c|c|c|c|c|c|}
\hline $\begin{array}{l}\text { Case } \\
\text { No. }\end{array}$ & Etiology & $\begin{array}{c}\text { Initial } \\
\text { device } \\
\left(\mathrm{cmH}_{2} \mathrm{O}\right)\end{array}$ & $\begin{array}{l}\text { Initial } \\
\text { course }\end{array}$ & $\begin{array}{l}\text { Period to } \\
\text { revision } \\
\text { (wk) }\end{array}$ & ADL & $\begin{array}{l}\text { IVP at } \\
\text { revision }\end{array}$ & Treatment & $\begin{array}{c}\text { Revised } \\
\text { device } \\
\left(\mathrm{cmH}_{2} \mathrm{O}\right)\end{array}$ & Outcome \\
\hline 1 & $\mathrm{~S}$ & DSV (10/40) & IMP & 8 & WC & normal & revision & SPAV & IMP \\
\hline 2 & $\mathrm{~S}$ & $\operatorname{DSV}(10 / 40)$ & IMP & 8 & $\mathrm{BR}$ & normal & revision & SPAV & IMP \\
\hline 3 & $\mathrm{~S}$ & DSV (10/40) & IMP & 3 & WC & normal & revision & DSV (5/30) & IMP \\
\hline 6 & $\mathrm{~S}$ & DSV (10/30) & $\mathrm{NC}$ & 2 & WC & high & revision & SPAV & IMP \\
\hline \multicolumn{10}{|c|}{ Overdrainage: } \\
\hline 7 & I & DSV (10/40) & IMP & 108 & walk & low & I \& D, revision & SPAV & IMP \\
\hline 8 & I & DSV $(10 / 40)$ & IMP & 24 & walk & normal & I \& D & $\begin{array}{l}\text { DSV } \\
\quad \text { retained }\end{array}$ & IMP \\
\hline
\end{tabular}

ADL: activity of daily living, BR: bedridden, DSV: dual switch valve, I: idiopathic, I \& D: irrigation and drainage, IMP: improved, IVP: intraventricular pressure, NC: no change, S: secondary, SPAV: Sophy pressure adjustable valve, WC: wheel chair, WOR: worse.

retained the DSV and has had no recurrence of subdural hematoma to date. Case 9 showed clinical deterioration immediately after ventriculopleural shunting and developed subdural hematoma. $\mathrm{He}$ required shunt revision (DSV $5 / 30$ to $10 / 50 \mathrm{cmH}_{2} \mathrm{O}$ ) and irrigation of the subdural hematoma. No other patient showed any symptoms or signs of overdrainage, except for the two patients with asymptomatic thin subdural effusion.

\section{Discussion}

The present study clearly shows that the DSV can regulate the IVP regardless of posture. The IVP in the supine position (OP1) was just below the SOP in most patients, whereas the IVP in the sitting position (OP2) was around zero or slightly below. Patients with pressure differential devices often suffer excessive negative IVP in the upright position (Table 3), ${ }^{3,6,11)}$ which is thought to be important in the development of overdrainage. ${ }^{4,16)}$ Selection of a high shunt opening pressure may reduce the risk of overdrainage in the upright position, but also increases the risk of underdrainage in the supine position. In contrast, the DSV provides different opening pressures depending on the patient's posture. Antisiphon devices (ASDs) can also regulate the IVP in the upright position. ${ }^{3,11)}$ However, the DSV has several advantages, especially regarding the functional role of the subcutaneous pressure. The ASD requires precise location, ${ }^{8,9)}$ whereas the DSV can be implanted anywhere in parallel to the body axis.

The present study indicates that the DSV prevents the majority of problems related to overdrainage. Few patients suffered the symptoms or signs of low intracranial pressure. The DSV operated especially well in the upright position, preventing the development of negative pressure. Unfortunately, chronic subdural hematoma occurred in three patients. Two of them had obviously suffered episodes of head trauma, but one of them had extremely negative IVP, and we could not identify the reason at the time of shunt revision. Another patient who underwent pleural shunting also showed extremely negative IVP, which probably originated in the negative intrathoracic pressure, which theoretically should be prevented by the DSV. These three patients all had idiopathic normal pressure hydrocephalus, suggesting that this disease requires a more delicate flow control mechanism.

The DSV seemed to present certain problems with the development of underdrainage. At least six patients who showed clinical improvement after shunt revision were thought to suffer from underdrainage despite patent shuntgraphy findings. These patients were almost all bedridden for a longer period after shunt placement, which may cause relatively high IVP induced by the shunt opening pressure of $10 \mathrm{cmH}_{2} \mathrm{O}$ in the supine position. Problems of underdrainage in bedridden patients require a lower pressure setting of $5 \mathrm{cmH}_{2} \mathrm{O}$, which is now available. Given that overdrainage occurred in the upright position and underdrainage in the supine position, the lower pressure device is expected to reduce problems with underdrainage without increasing the risk of overdrainage. Indeed no patient suffered underdrainage with a DSV allowing 
Table 3 Intraventricular pressure in the upright position

\begin{tabular}{|c|c|c|c|c|}
\hline Author (Year) & $\begin{array}{l}\text { Normal subjects } \\
\quad\left(\mathrm{cmH}_{2} \mathrm{O}\right)\end{array}$ & $\begin{array}{l}\text { Before shunt } \\
\left(\mathrm{cmH}_{2} \mathrm{O}\right)\end{array}$ & $\begin{array}{l}\text { Shunt with ASD } \\
\qquad\left(\mathrm{cmH}_{2} \mathrm{O}\right)\end{array}$ & $\begin{array}{l}\text { Shunt without ASD } \\
\qquad\left(\mathrm{cmH}_{2} \mathrm{O}\right)\end{array}$ \\
\hline $\begin{array}{l}\text { Fox et al. } \\
(1973)^{6) * *}\end{array}$ & & $-9 \sim 27$ & & $-34 \sim-12$ \\
\hline $\begin{array}{l}\text { McCullough and Fox } \\
(1974)^{11)^{* *}}\end{array}$ & & $-10 \sim 27($ mean 7.7$)$ & $-20 \sim 0($ mean -6.4$)$ & $-44 \sim 27($ mean -25.1$)$ \\
\hline $\begin{array}{l}\text { Chapman et al. } \\
(1990)^{3)^{*}}\end{array}$ & $-5 \sim 5$ & & $-15 \sim 35$ & $-7 \sim 3$ \\
\hline Present series*** & & $3.7 \sim 40.8$ (mean 14.3) & \multicolumn{2}{|c|}{$-12 \sim 6 \#($ mean -2.5$)$} \\
\hline
\end{tabular}

Zero reference level is at the level of the parietal scalp*, foramen of Monro**, or external auditory meatus***. \#Shunt with dual switch valve. ASD: antisiphon device.

Table 4 Occurrence of reprogramming, subdural fluid collection, and shunt survival in patients with pressure programmable devices

\begin{tabular}{llcccc}
\hline \multicolumn{1}{c}{ Author (Year) } & Device & $\begin{array}{c}\text { No. of } \\
\text { cases }\end{array}$ & Reprogramming & $\begin{array}{c}\text { SDFC } \\
\text { (required operation) }\end{array}$ & $\begin{array}{c}\text { Shunt survival/ } \\
\text { Follow-up period }\end{array}$ \\
\hline Lumenta et al. (1990) $^{10)}$ & SPAV & 74 & $50 \%$ & $4(3)$ & $85.1 \% / 16.2 \mathrm{mos}$ \\
Pollack et al. (1999) $^{14)}$ & $\mathrm{CH}$ & 194 & $66 \%$ & $\mathrm{ND}$ & $51 \% / 2 \mathrm{yrs}$ \\
Yamashita et al. (1999) $^{21)}$ & $\mathrm{CH}$ & 179 & $50.6 \%$ & $1(0)$ & $\mathrm{ND}$ \\
Zemack and Romner (2000) $^{22)}$ & $\mathrm{CH}$ & 583 & $42.2 \%$ & $38(25)$ & $74.6 \% / 1 \mathrm{yr}$ \\
Present series & DSV & 101 & $7.9 \%{ }^{*}$ & $5(3)$ & $85 \% / 27.4 \mathrm{mos}$ \\
\hline
\end{tabular}

${ }^{*}$ Required surgical revision. CH: Codman-Hakim, DSV: dual switch valve, ND: no description, SDFC: subdural fluid collection, SPAV: Sophy pressure adjustable valve.

the lower pressure setting of $5 \mathrm{cmH}_{2} \mathrm{O}$.

The biggest disadvantage of the DSV is that the opening pressure of the device cannot be changed without surgical intervention. Nevertheless, fewer patients required pressure changes than expected. About $50 \%$ (42.2-66\%) of previous series of patients with an adjustable valve have required reprogramming (Table 4), ${ }^{10,14,21,22)}$ whereas only eight of our patients $(7.9 \%)$ required shunt revision to correct inadequate drainage. Moreover, such underdrainage-related problems may be reduced by devices with a lower opening pressure. Therefore, the DSV shows high potential for reestablishing physiological CSF flow.

The DSV has several other important characteristics. Most importantly, the DSV is not affected by exposure to magnetic fields. Accidental resetting of the shunt opening pressure by the strong magnetic field of the magnetic resonance imager has been a problem for most pressure programmable devices. ${ }^{7,13)}$ Moreover, daily life commonly involves exposure to a wide variety of magnetic devices or fields. This special feature of the DSV gives a great sense of inner security to the patients, as well as the medical staff. No complications arising from the shunt device itself, such as device obstruction or accidental change of shunt opening pressure, occurred in this series. As a result, the shunt survival rate was satisfactory compared with recent reports about other devices (Table 4). These good characteristics are mostly due to the uncomplicated and robust structure of the DSV. ${ }^{2,15,17)}$

The DSV is a promising shunt device that can establish physiological IVP independent of posture followed by satisfactory clinical outcome in patients with hydrocephalus. However, the DSV cannot completely prevent problems caused by inadequate drainage.

\section{References}

1) Aschoff A, Kremer P, Benesch C, Fruh K, Klank A, Kunze S: Overdrainage and shunt technology. A critical comparison of programmable, hydrostatic and variable-resistance valves and flow-reducing devices. Childs Nerv Syst 11: 193-202, 1995

2) Borgbjerg BM, Gjerris F, Albeck MJ, Hauerberg J, Borgesen SE: Frequency and causes of shunt revisions in different cerebrospinal fluid shunt types. Acta Neurochir (Wien) 136(3-4): 189-194, 1995

3) Chapman PH, Cosman ER, Arnold MA: The relationship between ventricular fluid pressure and body position in normal subjects with shunts: A telemetric study. Neurosurgery 26: 181-189, 1990

4) Czosnyka M, Whitehouse H, Smielewski P, Simac S, Pickard JD: Testing cerebrospinal compensatory reserve in shunted and non-shunted patients: a guide 
to interpretation based on an observational study. J Neurol Neurosurg Psychiatry 60: 549-558, 1996

5) Czosnyka Z, Czosnyka M, Richards HK, Pickard JD: Posture-related overdrainage: comparison of the performance of 10 hydrocephalus shunt in vitro. Neurosurgery 42: 327-334, 1998

6) Fox JL, McCullough DC, Green RC: Effect of cerebrospinal fluid shunts on intracranial pressure and on cerebrospinal fluid dynamics. 2. A new technique of pressure measurements: results and concepts. 3. A concept of hydrocephalus. J Neurol Neurosurg Psychiatry 36: 302-312, 1973

7) Fransen P, Dooms G, Thauvoy C: Safety of the adjustable pressure ventricular valve in magnetic resonance imaging: problems and solutions. Neuroradiology 34: 508-509, 1992

8) Hassan M, Higashi S, Yamashita J: Risks in using siphon-reducing device in adult patients with normal-pressure hydrocephalus: bench test investigations with Delta valves. J Neurosurg 84: 634-641, 1996

9) Kremer P, Aschoff A, Kunze S: Risks of using siphonreducing devices. Childs Nerv Syst 10: 231-235, 1994

10) Lumenta CB, Roosen N, Dietrich U: Clinical experience with a pressure-adjustable valve SOPHY in the management of hydrocephalus. Childs Nerv Syst 6: 270-274, 1990

11) McCullough DC, Fox JL: Negative intracranial pressure hydrocephalus in adults with shunt and its relationship to the production of subdural hematoma. J Neurosurg 40: 372-375, 1974

12) Miethke $C$, Affeld $K: A$ new valve for the treatment of hydrocephalus. Biomed Tech (Berl) 39: 181-187, 1994

13) Orther $M$, Kostron H, Felber S: Transcutaneous pressure-adjustable valves and magnetic resonance imaging: an ex vivo examination of the CodmanMedos programmable valve and the Sophy adjustable pressure valve. Neurosurgery 40: 1050-1058, 1997

14) Pollack IF, Albright AL, Adelson PD: A randomized controlled study of a programmable shunt valve versus a conventional valve for patients with hydrocephalus. Hakim-Medos Investigator Group. Neurosurgery 45: 1399-1408, 1999

15) Puca A, Anile C, Maria G, Rossi G: Cerebrospinal fluid shunting for hydrocephalus in adult: factors related to shunt revision. Neurosurgery 29: 822-826, 1991

16) Pudenz RF, Foltz EL: Hydrocephalus: overdrainage by ventricular shunts. A review and recommendations. Surg Neurol 35: 200-212, 1991

17) Saint-Rose C: Shunt obstruction. A preventable complication? Pediatr Neurosurg 19: 156-164, 1993

18) Sprung C, Miethke C, Trost HA, Lanksch WR, Stolke D: The dual-switch valve: A new hydrostatic valve for the treatment of hydrocephalus. Childs Nerv Syst 12: 573-581, 1996

19) Trost HA: Is there a reasonable differential indication for different hydrocephalus shunt systems? Childs Nerv Syst 11: 189-192, 1995

20) Trost HA, Sprung C, Lanksch WR, Stolke D, Miethke C: Dual-switch valve: clinical performance of a new hydrocephalus valve. Acta Neurochir Suppl 71: 360-363, 1998

21) Yamashita N, Kamiya K, Yamada K: Experience with a programmable valve shunt system. J Neurosurg 91: 26-31, 1999
22) Zemack G, Romner B: Seven years of clinical experience with the programmable Codman Hakim valve: a retrospective study of 583 patients. J Neurosurg 92: 941-948, 2000

Address reprint requests to: Akira Tsunoda, M.D., Department of Neurosurgery, Koshigaya Municipal Hospital, 10-47-1 Higashikoshigaya, Koshigaya, Saitama 343-0023, Japan.

e-mail: t-akira@mua.biglobe.ne.jp

\section{Commentary}

Dual switch valve (Miethke) is a newly designed hydrostatic valve which regulates the intraventricular pressure by changing two different valve-chambers in parallel depending on the posture of the patient. The authors report the usefulness of this valve in 101 consecutive cases of hydrocephalus. They demonstrate that the intraventricular pressure is kept in a relatively small range in their valve pressure setting. A problem for clinical use of the dual switch valve is the difficulty in selection of appropriate valve pressure in an individual patient. It may be useful to overcome this problem to investigate more precisely the variability of intraventricular pressure in their patients.

Masatsune IsHIKaWA, M.D. Department of Neurosurgery

Kitano Hospital Osaka, Japan

Shunt surgery has been well documented as a meaningful solution for patients with hydrocephalus, however, new balance of CSF flow after shunt implantation may become a cause of new problems, such as overdrainage or underdrainage, and a minority of patients have to undergo shunt reprogramming or revision. A recent study from Tsunoda and Maruki demonstrated a new device for shunt surgery in patients with hydrocephalus. With the unique technique of the dual switch valve (DSV) device, the research has achieved the best result of shunt surgery in literature of only $7.9 \%$ shunt revision due to inadequate drainage. The obvious advantage of the DSV device is the reduction of the incidence rate for overdrainage by position change (upright). Physiological regulation of IVP is regarded as an ideal of design of the shunt system. Further studies need to be done to complete understanding of the effects of the shunt device in the aspects of new CSF flow balance after shunting, and design of an advanced shunt system is encouraged.

Yazhuo ZHANG, M.D. Department of Neurosurgery Beijing Neurosurgical Institute Beijing, P.R.C. 